\title{
Biodiversity Features of the Main Steppe Communities in In- ner Mongolia and their Relations to Climate and Grazing
}

\section{YONGHONG}

Instituse of Botany. Chinese Academy of Sciences, Beijing 100044

(Received May 3. 1993: Revised June 12, 1993)

\begin{abstract}
One hundred steppe communities were investigated on climate gradients in the central Inner Mongolia. The main communities were dominanted by Stipa gobica. S. breviflora. S. krylovii, S. grandis, S. baicalensis. Aneurolepidium chinense. Filifolium sibiricum and Festuca dahurica, etc. . Their species diversity features were analyzed in relation to climate factors and grazing intensities. The results showed that species richness $(\mathrm{S})$ in steppe communities was positively correlated with precipitation $\left(S=-5.1 \cdot e^{0.00627 P^{2}}\right.$; $r=0.85, p=0.001)$, but negatively with temperature (T) $\left(S=50.9 \cdot e^{-0.225 T} ; r=0.92 . p<0.001\right)$ - The species richness decreased as climate aridity (A) increased $\left(S=-41.81+48.03 e^{1 / A}, p<0.001\right)$. The communitie diversity had similar tendence of change with species richness along climate gradient. The highest diversity always appeared at moderate level of grazing intensity for a certain commuity. which was due to the prevention of exclusive competition of species by moderate grazing. An integrated schematic model on the relationship of community diversity with climate aridity and stocking rate was proposed.
\end{abstract}

Key Worlds Inner Mongolia, steppe, biodiversity, climate. grazing

\section{INTRODUCTION}

Temperate grassland is one of the 5 biomes recommended by IUBS-SCOPE-UNESCO for inventoring and monitoring biodiversity in the first instance (Di Castri, et al. 1992). The steppe on the Mongolian plateau is situated in the easternmost part of the Eurasian steppe region, and is highly representative of the geographical and ecological conditions (Lavrenko. 1970). It has been traditionally used as rangelands since the ancient time. But the unrational utilization during the last several decades has resulted in serious degradation ( $\mathrm{Li}, 1991$ ), and loss of its species diversity. Among various human activities, livestock grazing is the most widely distributed disturbance influencing species diversity. Numerous scientists (Grime, 1973; Naveh et al., 1980; Bakker, 1989) studied the relationship of community diversity with grazing and other disturbances in different grasslands and arrived at similar conclusions that moderate levels of disturbance (including grazing) were the prerequisites for a high species diversity. This kind of studies did not start until present in the steppe grasslands of Inner Mongolia. This paper focused on the general features of species diversity in the main steppe communities of Inner Mongolia, especially on their relationship of geographical patterns with climate factors, based on which, the diversity changes of different steppe communities under grazing influence were analyzed, and a schematic model on 


\section{直接copy本文内容时会有误差，请注意核对！}

the relationships between community diversity, climate aridity and stocking rate was proposed.

\section{STUDY AREA}

The study area lies on the southeast part of Mongolian Plateau at $111^{\circ} 10^{\prime} \sim 117^{\circ} 50^{\prime} \mathrm{E}$ and $41^{\circ} 20^{\prime} \sim 45^{\circ} 40^{\prime} \mathrm{N}$ with an altitude between $900 \sim 1500 \mathrm{~m}$ declining from southeast to northwest. It is under a temperate, semiarid climate with a gradient also from southeast to northwest. Along this direction, annual precipitation decreases from $370 \mathrm{~mm}$ to $170 \mathrm{~mm}$. mean annual temperature increases from $-0.5{ }^{\circ} \mathrm{C}$ to $5 .{ }^{\circ} \mathrm{C}$, and climate aridity (Penman's) increases from 2 to 6 . Chernozem, chestnut and brown calcareous soils are also successively distributed along the direction. Steppe is a zonal vegetation, dominated by a series species of stipa and Aneurolepidium chinese, Filifolium sibiricum, Festuca hahurica, etc.

\section{STUDY METHODS}

In order to cover all the steppe vegetation zones and inventory all the main steppe communities , two inventory itinerairies along a climate gradient from desert-steppe zone to forest-steppe zone were adapted. One handred steppe sites were investigated during plant growing season (July August). Species composition was recorded with nest-quadrat of 8 $\mathrm{m}^{2}$; and the species surrounding the quadrat in the same homogeneous site were also recorded. The density, height and aerial phytomass were measured with 5 quadrats of $1 \mathrm{~m}^{2}$ in each site. Grazing intensities were divided into several classes (light, light-moderate, moderate, heavy-moderate, heavy) and estimated during the investigation according to the distance of site to water resources or villages, the livestock excrements and the grassland situations. The gradients of climate factors were also divided into several classes (ranges), and the situation of climate factors for each site were determined according to the climatological data collected from the nearby meteorological stations. The communities were clustered according to their first dominant species, and then the main communities were chosen. Their species richness (S) was analyzed in relation to climate factors by regression techniques. The evenness $(\mathrm{E})$ and diversity $(\mathrm{H})$ indices of these communities were calculated by Shannon's formula $\left(H=-\sum P i \cdot L n P i\right.$ and $E=H / L n s$; where $P i$ is the dry matter proportion of species i). Their relationships to climate factors were revealed by locating them on a hydrothermic plane according to their regional preferences to precipitation and temperature. The preference of a community on a factor gradient was calculated on the basis of its presence in different classes of the factor by formula the following (Daget et al., 1982) :

$$
P=\sum\left(F_{k} \cdot K\right) / \sum F_{k}, F_{k}=N_{k p} / N_{k} \cdot N_{p} / N,
$$

where $N$ was the total number of sites; $N_{p}$, the number of sites with the presence of community i; $N_{k}$, the number of sites when the factor is in class $k ; N_{k p}$, the number of sites in class $\mathrm{k}$ with the presence of community $\mathrm{i} ; k$, the class order of a factor along its gradient. The diversity features of these communities on different grazed sites were compared, and the general changes of diversity features on grazing gradients were revealed. The integrated relationships of community diversity with climate aridity and stocking rate were illustrated with a schematic model. 


\section{RESULTS}

\section{Species diversity features of the main steppe communities in relation to climate}

The 100 inventoride sites were clustered in 28 community-types according to their first dominant species, among which, 8 types were frequently recorded and distributed on the zonal habitat and lightly utilized. They were considered as the representative for diversity analysis. Their species richness, community evenness and diversity indices. as well as other related features were shown in table.

\section{TABLE}

Diversity and structure features of the main steppe communities in Inner Mongolia

\begin{tabular}{|c|c|c|c|c|c|c|c|}
\hline \multirow{2}{*}{$\begin{array}{c}\text { Community Numb. } \\
\text { name }{ }^{1)} \text { of } \\
\text { site }\end{array}$} & \multicolumn{2}{|c|}{$\begin{array}{c}\text { Species } \\
\text { richness }^{2)}\end{array}$} & \multirow{3}{*}{$\begin{array}{c}\begin{array}{c}\text { Diversity } \\
\text { index } \\
(\mathrm{H})\end{array} \\
1.25\end{array}$} & \multirow{3}{*}{$\begin{array}{c}\begin{array}{c}\text { Evenness } \\
\text { index } \\
\text { (E) }\end{array} \\
0.41\end{array}$} & \multirow{3}{*}{$\begin{array}{r}\begin{array}{c}\text { Height } \\
(\mathrm{cm})\end{array} \\
6.9\end{array}$} & \multirow{3}{*}{$\begin{array}{c}\begin{array}{c}\text { Cover with } \\
\text { ranges } \\
(\%)\end{array} \\
15(5 \sim 25)\end{array}$} & \multirow{3}{*}{$\begin{array}{c}\begin{array}{c}\text { Phytomass } \\
\left(\mathrm{gDM} / \mathrm{m}^{2}\right)\end{array} \\
11.28\end{array}$} \\
\hline & $\mathrm{S}_{1}$ & $\mathrm{~S}_{2}$ & & & & & \\
\hline STGOB 10 & 12.0 & 17.6 & & & & & \\
\hline STBRE & 14.5 & 20.0 & 2.06 & 0.65 & 7.0 & $22(15 \sim 30)$ & 20. 92 \\
\hline STKRY 6 & 21.3 & 27.3 & 2.27 & 0.66 & 14.9 & $28(15 \sim 70)$ & 37.91 \\
\hline STGRA & 27.9 & 33.9 & 1.91 & 0.48 & 26.0 & $47(25 \sim 75)$ & 125.71 \\
\hline STBAI & 41.7 & 47.3 & 1.99 & 0.63 & 47.3 & $65(40 \sim 90)$ & 259. 90 \\
\hline ANCHI 17 & 23. 1 & 29.6 & 2.49 & 0.67 & 33.0 & $61(35 \sim 95)$ & 270.48 \\
\hline FISIB 5 & 41.8 & 45.4 & 2. 78 & 0.70 & 23. 3 & $60(30 \sim 90)$ & 167.39 \\
\hline FEDAH 3 & 33.3 & 40.7 & 1. 99 & 0.43 & 15.3 & $60(30 \sim 90)$ & 95.20 \\
\hline
\end{tabular}

1). The abbreviations of the commuity names, which are also used in Fig. 1 and Fig. 2. are as follows: STGOB-Stipa gobica. STBRE - Stipa breviflora. STKRY - Stipa krylovï. STGRA - Stipa grandis. STBAI-Stipa baicalensis. ANCHI - Aneurolepidium chinese. FISIB-Filifolium sibiricum and FEDAH - Festuca dahurica.

2). Species richness is the mean species numbers recorded in $8 \mathrm{~m}^{2}$ quadrats $\left(\mathrm{S}_{1}\right)$ and in each site $\left(\mathrm{S}_{2}\right)$.

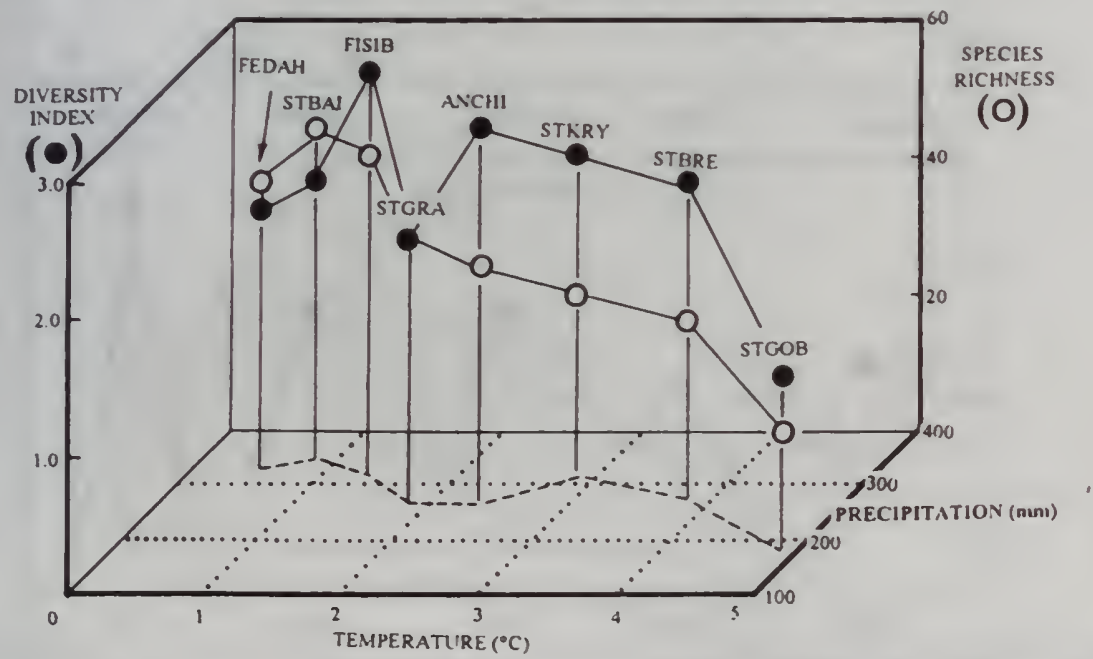

Fig. 1, Diversity features of the main steppe communities in Inner Mongolia and their relations to climate factors. 


\section{直接copy本文内容时会有误差，请注意核对！}

The other communitiy-types were dominated by Artemisia frigida, Agropyron cristatum, Cleistogenes songorica, C. syuarrosa and Carex duriuscula, etc. They were mainly the derived types of the above 8 communities by retrogressive succession under grazing influence. Their diversity features were analyzed in relation to grazing intensity.

Table suggested that Stipa gobica community had the lowest species richness, community evenness and diversity indices, while Stipa baicalensis and Filifolium sibiricum communities, the highest. The other communities were at moderate levels. The difference of species diversity in steppe communities were mainly correlated with environmental conditions, especially with climate factors. Fig. 1 showed the preferences of these communities on the hydrothermic plane (precipitation-temperature), which indicated that species richness (S) was positively correlated with precipitation $(\mathrm{P})\left(S=-5.1 \cdot e^{0.00627 p} ; r=0.85, p=0.001\right)$, but negetively correlated with temperature $(\mathrm{T})\left(S=50.9 \cdot e^{-0.225 T} ; r=0.92, p<0.001\right)$ . This suggested that the species richness decreased as climate aridity increased. The relationship between species richness in the 100 sites and climate aridity (A) could be expressed by an equition: $S=-41.81+48.03 e^{1 / \mathrm{A}}, p<0.001$.

The diversity index of these communities had similar tendence of change on the hydrothermic plane, that is, the diversity decreased as climate aridity increased. But the location of Festuca dahurica or Stipa baicalensis communities did not reflect its real preferences on precipitation and temperature gradients since they were recorded mainly on hills with relatively high altitude in the research area.

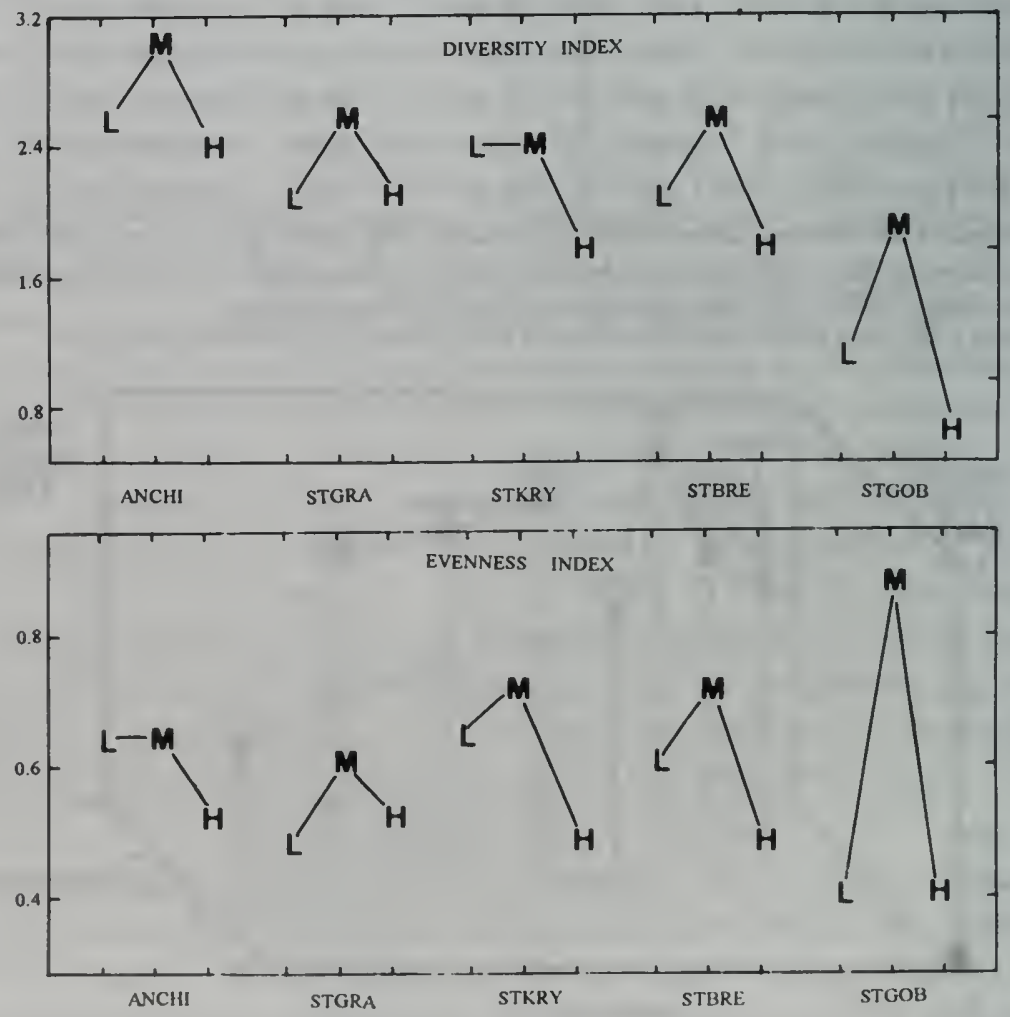

Fig. 2. Diesity and evenness features of the 5 main steppe communities in Inner Mongolia on a grazing gradient (L-lightly, M-moderately, H-heavyly grazed sites).

2 Diversity features of the main steppe communities on grazing gradients 
In this field inventory. we did not find he grazing series of Stipa baicalensis. Festuca dahurica or Filifolium sibiricum communities; while the series of the other 5 communities were identified with PCA techiques, based on their species dominance and the grazing intensities estimated in each site ( $\mathrm{Li}, 1991)$. Their diversity and evenness indices along grazing gradients were calculated and summerized in Fig. 2. It suggested that the highest diversity and evenness always appeared on moderately grazed sites for all 5 communities, which was similar to the results of other researchers in different grasslands (Bakker. 1989), and to the results of the detailed studies on the biodiversity of Stipa grandis and Aneurolepidium chinese steppe communities in two concrete grazing gradients. The high diversity at moderate levels of grazing intensity is due to the moderate grazing that prevents exclusive competition of dominanct species (Grime, 1973), and at the same time, has no restrictions to the development of other species. Fig. 2 also indicated that the communities in arid habitat had larger amplitude of evenness under grazing influence than those in humid habitat.

\section{An integrated schematic model on the relationships of community diversity with climate aridity and stocking rate}

According to the above analysis, in a large geographical region. community diversity depended mainly on climate factros; while in a relatively small area, it was greatly influenced by animal grazing. These two crossed functions could be expressed with an integrated scheme (Fig. 3). Since the stocking rates of light, moderate and heavy grazing varied among different communities, they were standarized according to their aerial phytomass. Fig. 3 showed that the diversity increased as climate aridity decreased. and moderate grazing intensity led to a highest diversity. The stockin rates under which the community had the highest diversity increased with the increase of community phytonnass, and therefore, with the increase of climate humidity.

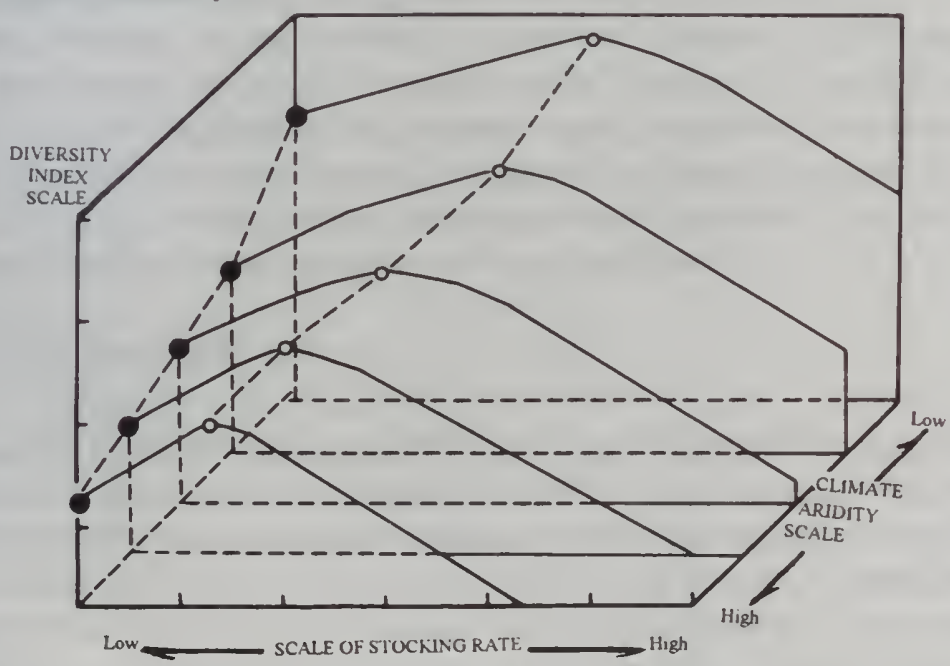

Fig. 3. An integrated schematic model on the relationships of community diversity with climate aridity and stocking rate. 


\section{CONCLUSIONS}

In the steppe region of Inner Mongolia, the geographical patterns of the species richness, community evenness and diversity of main steppe formations depended mainly on climate factors. The community diversity decreased as temperature increased or the precipitation decreased, that is, the increase of climate aridity. In a relatively small area, for a certain community, livestock grazing was the most important factors influencing diversity. Moderate grazing can prevent exclusive competition of species and lead to high community evenness and diversity.

\section{REFERENCES}

Bakker J P, 1989. Nature management by grazing and cutting. Geobot. 14, Kluwer Acad. Publ., 11 17 Daget Ph. M Godron, 1982. Analyse fréquentielle de l'écologie des éspèces dans les communautés. Collection d'écologie 18., Masson, 107 133

di Castri F, J R Vernhes, T Younes, 1992. Inventorying and monitoring biodiversity. Special Issus-27, biology International, IUBS, 28

Grime J P, 1973. Control of species diversity in herbaceous vegetation. J. Environ. Manage., Vol. 1: 151 $\sim 167$

Laverenko E M, 1970. The provincial division of the subregion of 'Centre of Asia' of the Eurasian steppe region. J. Botany, 55(12) (in Russian)

Li YongHong, 1991. The current situation of the steppe rangeland use in Inner Mongolia:-relationships of grassland structures with grazing. The proceed. of the IVth Intl Range. Congr., Montpellier, Fance. (in press)

Naveh Z, Whittaker R H, 1980. Structural and floristic diversity of shrublands and woodlands in Northern Israel and other Mediterranean areas. Veget. 41: 171 190 